\title{
CORRELATION OF FUNCTIONAL RECOVERY WITH MYOCARDIAL BLOOD FLOW, GLUCOSE UPTAKE, AND MORPHOLOGIC FEATURES IN PATIENTS WITH CHRONIC LEFT VENTRICULAR ISCHEMIC DYSFUNCTION UNDERGOING CORONARY ARTERY BYPASS GRAFTING
}

Christophe Depré, MD, PhD

Jean-Louis J. Vanoverschelde, MD, PhD

Bernhard Gerber, MD

Marcel Borgers, PhD

Jacques A. Melin, MD, $\mathrm{PhD}$

Robert Dion, MD
Objective: Our objective was to investigate the influence of preoperative myocardial ultrastructure and metabolism on recovery of contractile function after coronary artery bypass grafting in patients with coronary artery disease and left ventricular dysfunction. Methods: Dynamic positron emission tomog raphy with ${ }^{13} \mathrm{~N}$-ammonia and ${ }^{18} \mathrm{~F}$-deoxyglucose was used to assess myocardial perfusion and glucose uptake in 53 patients scheduled for coronary revascularization because of coronary artery disease and left ventricular dysfunction. The degree of tissue fibrosis and the presence of potentially reversible alterations of cardiomyocytes (loss of myofilaments and accumulation of glycogen) were quantified from transmural biopsy specimens. These were harvested from the center of the dysfunctional area during the operation and analyzed with a light microscope. The recovery of contractile performance was assessed from the changes in left ventricular function at contrast ventriculography or echocardiography before and 6 months after the operation. Results: According to postoperative changes in regional wall motion, left ventricular function was considered to have improved in $\mathbf{3 4}$ patients, whereas dysfunction persisted in 19 patients. In patients with improved wall motion, ejection fraction rose by $12 \%$ and end-systolic volume decreased by $28 \%$. By contrast, in patients with persistent dysfunction, ejection fraction decreased by $6 \%$ and end-systolic volume increased by $25 \%$. Before revascularization, myocardium with reversible dysfunction displayed higher levels of absolute myocardial blood flow, higher myocardial glucose uptake, less tissue fibrosis, and more altered cardiomyocytes than myocardium with persistent dysfunction. Significant correlations were found between regional blood flow and the surface of the biopsy specimen covered by fibrosis, as well as between glucose uptake and the density of altered cardiomyocytes. Conclusion: In patients with left ventricular ischemic dysfunction, the recovery of regional and global left ventricular function after surgical revascularization is associated with higher preoperative blood flow and glucose uptake, with less tissue fibrosis and a higher amount of viable cardiomyocytes in the dysfunctional area. The current study thus confirms the value of noninvasive preoperative metabolic imaging for identification of residual viable myocardium and for prediction of the functional outcome after revascularization. (J Thorac Cardiovasc Surg 1997;113:371-8)
From the Divisions of Cardiology and Cardiovascular Surgery and the Positron Emission Tomography Laboratory, University of Louvain Medical School, Brussels; and Janssen Research Foundation, Beerse, Belgium.

Received for publication May 6, 1996; revisions requested August 6, 1996; revisions received Sept. 4, 1996; accepted for publication Sept. 9, 1996.

Supported by grant 3-4522-89 from the "Fonds National de la Recherche Scientifique et Médicale" and by the "Action de Recherche Concertée" 91/96-146.
Read at the Seventy-sixth Annual Meeting of The American Association for Thoracic Surgery, San Diego, Calif., April 28-May 1, 1996.

Address for reprints: Christophe Depré, MD, PhD, Division of Cardiology, University of Louvain Medical School, Avenue Hippocrate, 10-2881, B-1200 Brussels, Belgium.

Copyright $(01997$ by Mosby-Year Book, Inc.

$0022-5223 / 97 \$ 5.00+0 \quad \mathbf{1 2 / 6 / 7 7 8 5 3}$ 
P revious studies have shown that chronic left ventricular dysfunction induced by coronary artery disease does not always result from irreversible tissue damage and, to some extent, can be reversed by coronary revascularization. ${ }^{1-3}$ These observations have led to the concept of residual myocardial viability in which poorly contractile myocardium that improves in the postoperative period is deemed "hibernating" or "viable," whereas myocardium that remains dysfunctional despite revascularization is considered to be infarcted or "nonviable." The recovery of contractile function after revascularization helps in important ways to reduce long-term mortality in patients with coronary artery disease. ${ }^{4,5}$ Thus the preoperative identification of residual viable myocardium has commanded considerable attention and has fostered the development of several new modalities aimed at predicting the return of left ventricular function after revascularization. Because reversibly dysfunctional myocardium must retain sufficient metabolic activity to maintain basal cell functions, ${ }^{6}$ simultaneous assessment of regional myocardial blood flow and metabolism with positron emission tomography (PET) has emerged as a safe, noninvasive, and accurate means of predicting functional recovery after revascularization. ${ }^{7-9} \mathrm{We}$ and others have recently reported on the presence of characteristic ultrastructural alterations in ischemically compromised myocardium and their potential relation to the metabolic changes that were shown to occur with PET in this tissue. ${ }^{10-12}$ In the current study, we summarized the data accumulated over the past 5 years in 53 patients undergoing coronary artery bypass grafting (CABG) in whom flow and metabolic data, obtained with PET before the operation, were correlated with the results of a detailed morphometric analysis of a transmural biopsy specimen harvested from the center of the dysfunctional area. Our data further substantiate the value of the preoperative assessment of myocardial viability for the prediction of postoperative improvement in left ventricular function.

\section{Methods}

Study population. The study comprised 53 patients ( 45 men and 8 women, mean age $60 \pm 11$ years, range 27 to 75 years) with significant left anterior descending coronary artery disease (defined as $>75 \%$ stenosis of the luminal diameter) and severe anterior dysfunction. Patients were considered eligible for inclusion into the study if they had (1) severe anterior wall dysfunction at contrast cineventriculography, (2) proximal left anterior descending coronary artery disease suitable for $\mathrm{CABG}$, (3) complete revascularization of the dysfunctional area, and (4) absence of perioperative myocardial infarction. Thirty-seven patients had a previous Q-wave myocardial infarction, the most recent occurring 30 days before inclusion into the study. Six patients had type II diabetes mellitus. All patients underwent successful CABG at an average of 53 days after the PET study; the left internal thoracic artery was used to graft the left anterior descending coronary artery. The study protocol was approved by the Ethical Committee of the University of Louvain Medical School.

Selective coronary arteriography was performed in every patient at an average of 34 days before the PET study. A complete occlusion or a severe proximal stenosis of the left anterior descending coronary artery was found in each case. Seven patients had one-vessel disease, 15 patients had two-vessel disease, and 31 patients had three-vessel disease. Two patients also had left main stenosis. Contrast cineventriculography, from the 30-degree right anterior oblique projection, was performed in 16 patients before and again 6 months after revascularization to assess the recovery of regional and global left ventricular function. Left ventricular volumes at end-diastole and end-systole were calculated by use of Simpson's method. Regional wall motion was assessed in five segments (anterobasal, anterolateral, apical, inferior, and posterobasal) by two experienced observers. Each segment was defined as (1) normal, (2) hypokinetic, or (3) akinetic. A wall motion score for the segments perfused by the left anterior descending coronary artery was calculated by summing the scores of the anterobasal, anterolateral, and apical segments.

Resting two-dimensional echocardiograms were obtained before and again 6 months after revascularization in the 37 patients who did not undergo repeated contrast cineventriculography. Images from the left parasternal short- and long-axis views and from the apical four- and two-chamber views were digitized on-line as previously described. ${ }^{13}$ Regional wall motion was assessed in 16 segments and defined as (1) normal, (2) hypokinetic, or (3) akinetic. A wall motion score for the segments supplied by the left anterior descending coronary artery was calculated by summing the scores of the mid-anterior, lateral-apical, and anterior-apical segments. Left ventricular volumes at end-diastole and end-systole were calculated from the apical four- and two-chamber views by use of Simpson's method.

Follow-up. Repeated contrast ventriculography $(n=$ 16) or two-dimensional echocardiography $(n=37)$ was obtained 6 months after the operation. Patients were considered to have improvement in function after revascularization if ejection fraction increased by at least $5 \%$ and regional wall motion score improved by at least one full grade from baseline to the follow-up study. Similarly, patients were considered to have persistent dysfunction if ejection fraction did not improve, if regional wall motion failed to improve at follow-up, or both.

PET. PET acquisition was performed with an ECAT III one-ring tomograph or an ECAT EXACT HR multislice tomograph (CTI, Knoxville, Tenn.). So that the dietary state would be standardized, myocardial glucose uptake was maximized by intravenous infusion of a $10 \%$ dextrose in water solution ( $15 \mu \mathrm{g} / \mathrm{kg}$ per minute) in 13 
Table I. Definitions relevant to glucose metabolism

\begin{tabular}{|c|c|}
\hline Metabolic concept & Definition \\
\hline FDG uptake & $\begin{array}{l}\text { Apparent overall }{ }^{18} \mathrm{~F} \text { activity in a given segment of the myocardium; always expressed in relative terms } \\
\text { as percent of maximal activity at the same imaging level. }\end{array}$ \\
\hline Mismatch pattern & $\begin{array}{l}\text { Discordant reduction of overall levels of }{ }^{18} \mathrm{~F} \text { and }{ }^{13} \mathrm{~N} \text { in a given myocardial segment of the myocar- } \\
\text { dium. }\end{array}$ \\
\hline Match pattern & $\begin{array}{l}\text { Concordant reduction of overall levels of }{ }^{18} \mathrm{~F} \text { and }{ }^{13} \mathrm{~N} \text { in a given myocardial segment of the myocar- } \\
\text { dium. }\end{array}$ \\
\hline Glucose uptake & $\begin{array}{l}\text { Absolute quantity of glucose taken up by the myocardium per unit of time; requires dynamic FDG } \\
\text { imaging; expressed as } \mu \mathrm{mol} \cdot(\mathrm{min} \cdot 100 \mathrm{gm})^{-1} \text {. }\end{array}$ \\
\hline Normalized glucose uptake & $\begin{array}{l}\text { Ratio of the absolute glucose uptake in the risk region to that in a remote normal region; expressed } \\
\text { as percent of remote. }\end{array}$ \\
\hline
\end{tabular}

Table II. Clinical and angiographic characteristics

\begin{tabular}{|c|c|c|c|c|}
\hline & $\begin{array}{c}A l l \\
(n=53)\end{array}$ & $\begin{array}{c}\text { Reversible } \\
\text { dysfunction } \\
(n=34)\end{array}$ & $\begin{array}{c}\text { Persistent } \\
\text { dysfunction } \\
(n=19)\end{array}$ & $p$ Value \\
\hline Age (yr) & $60 \pm 11$ & $59 \pm 12$ & $61 \pm 11$ & NS \\
\hline Sex & $45 \mathrm{M}, 8 \mathrm{~F}$ & $28 \mathrm{M}, 6 \mathrm{~F}$ & $17 \mathrm{M}, 2 \mathrm{~F}$ & NS \\
\hline Anterior $\mathrm{Q}$ waves & $37 / 53$ & $20 / 34$ & $17 / 19$ & 0.05 \\
\hline \multicolumn{5}{|l|}{ No. of diseased vessels } \\
\hline One vessel & $7 / 53$ & $5 / 34$ & $2 / 19$ & \\
\hline Two or three vessels & $46 / 53$ & $29 / 34$ & $17 / 19$ & NS \\
\hline \multicolumn{5}{|l|}{ CCS class } \\
\hline $\mathrm{I}+\mathrm{II}$ & $40 / 53$ & $26 / 34$ & $14 / 19$ & \\
\hline $\mathrm{III}+\mathrm{IV}$ & $13 / 53$ & $8 / 34$ & $5 / 19$ & NS \\
\hline \multicolumn{5}{|l|}{ NYHA class } \\
\hline $\mathrm{I}+\mathrm{II}$ & $42 / 53$ & $29 / 34$ & $13 / 19$ & \\
\hline $\mathrm{III}+\mathrm{IV}$ & $11 / 53$ & $5 / 34$ & $6 / 19$ & NS \\
\hline End-diastolic volume (ml) & $199 \pm 59$ & $184 \pm 57$ & $228 \pm 55$ & 0.003 \\
\hline End-systolic volume (ml) & $128 \pm 55$ & $117 \pm 54$ & $148 \pm 51$ & 0.02 \\
\hline Ejection fraction $(\%)$ & $37 \pm 12$ & $38 \pm 14$ & $36 \pm 10$ & NS \\
\hline Wall motion score & $7.8 \pm 1.1$ & $7.6 \pm 1.2$ & $8.1 \pm 0.9$ & NS \\
\hline
\end{tabular}

CCS, Canadian Cardiovascular Society; NYHA, New York Heart Association; NS, not significant.

patients or by use of the hyperinsulinemic-euglycemic glucose clamp technique ${ }^{14}$ in the remaining 40 patients. Myocardial perfusion was assessed with ${ }^{13} \mathrm{~N}$-ammonia and exogenous glucose uptake with ${ }^{18} \mathrm{~F}$-deoxyglucose (FDG). The tracers were injected intravenously over a 30-second period by means of an infusion pump. One dynamic midventricular transaxial study was analyzed per patient for dynamic imaging. For acquisitions performed with the ECAT EXACT HR tomograph, this slice was obtained by summing four smaller slices of $3.2 \mathrm{~mm}$ to obtain a slice width comparable with that from the ECAT III tomograph $(15 \mathrm{~mm})$. Three large irregular volumes of interest were assigned to each image of the left ventricular myocardium and a circular volume of interest was assigned to the center of the left ventricular blood pool. One of the volumes of interest encompassed the interventricular septum, another the anterior wall, and the remaining the lateral free wall of the left ventricle. The lateral free wall was considered as the remote normal segment if no dysfunction was present on two-dimensional echocardiograms. Counts were corrected for partial volume and spillover effects by means of a specially developed Monte-
Carlo simulation, ${ }^{11}$ as well as for dead-time losses. The volumes of interest drawn on the FDG study were copied onto the ${ }^{13} \mathrm{~N}$-ammonia study. Identical placement of the volumes of interest on all dynamic studies was ascertained, and manual correction for patient movement was done if necessary.

${ }^{13} \mathrm{~N}$-ammonia and ${ }^{18} \mathrm{~F}$-FDG cross-sectional images were analyzed with an operator-interactive computer program using circumferential profiles. ${ }^{11}$ The program normalizes ${ }^{18} \mathrm{~F}$ and ${ }^{13} \mathrm{~N}$ counts within a given myocardial cross section to maximal activity in the same ventricular slice. Each cross section of the left ventricle was divided into serial 10-degree segments. Activity within each segment was expressed in relative terms (reported as relative ${ }^{18} \mathrm{~F}$ and ${ }^{13} \mathrm{~N}$ uptake) as percent of maximal activity. A pattern of flow/metabolism "mismatch" was considered to be present when the relative ammonia uptake was lower than the minimal range of the normal volunteers (70\%) and when the FDG/ammonia ratio exceeded $1.2 .{ }^{11}$ For this analysis, the activity was normalized to peak ${ }^{13} \mathrm{~N}$ ammonia activity. PET data were quantified as previously described. ${ }^{11,15}$ Regional myocardial perfusion was quan- 

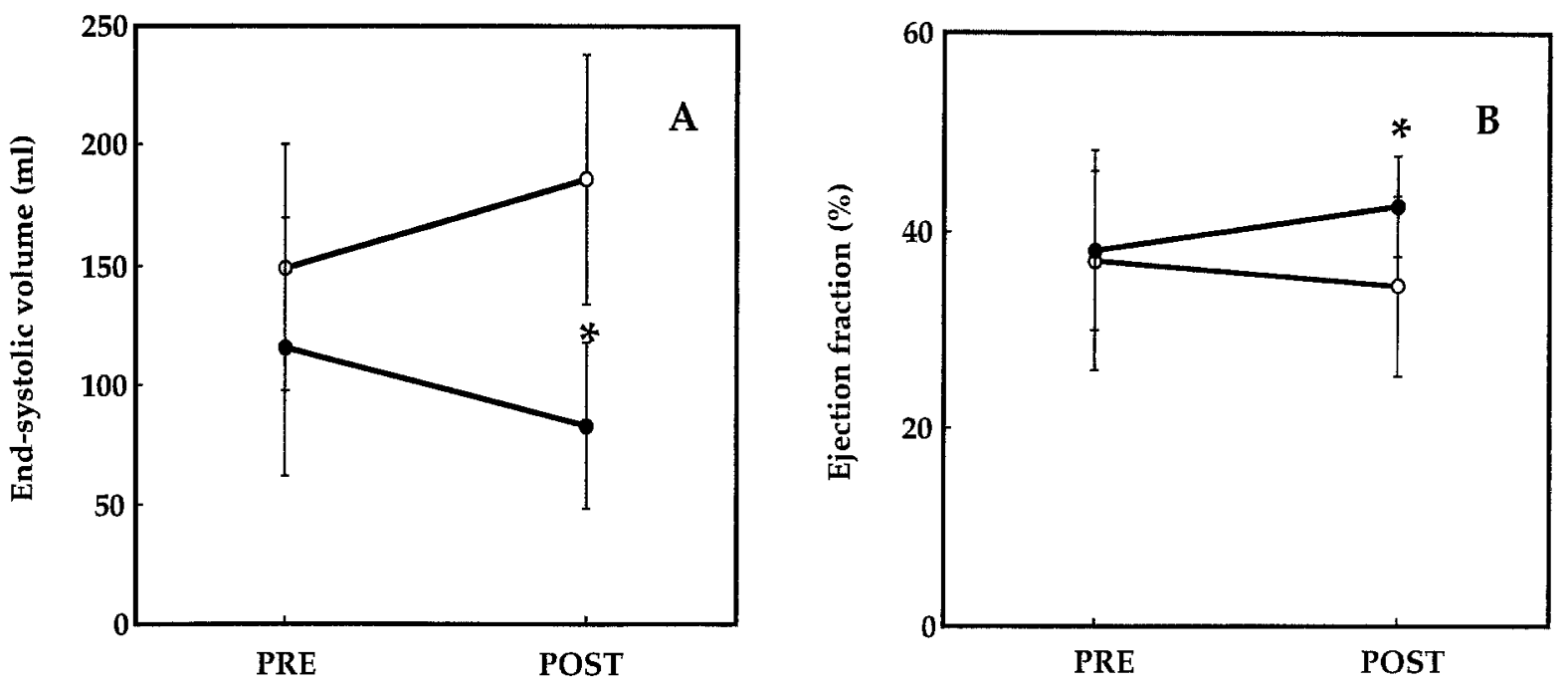

Fig. 1. End-systolic volume (A) and ejection fraction (B) in patients with reversible (closed circles) and persistent (open circles) dysfunction before the operation (PRE) and at follow-up (POST). ${ }^{*} p<0.05$.

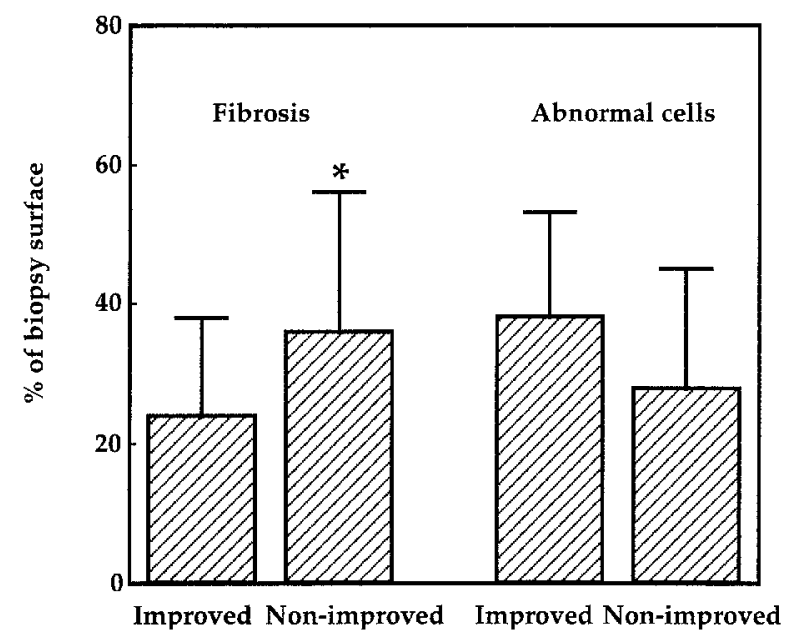

Fig. 2. Bar graph showing the percentage of surface of the biopsy specimen covered by fibrosis (left) and abnormal cardiomyocytes (right) in patients with reversible and persistent dysfunction (mean \pm standard deviation). ${ }^{*} p<$ 0.05 .

tified by use of a three-compartment model, ${ }^{15}$ and the Patlak graphic analysis was used to estimate myocardial glucose uptake. ${ }^{16}$ The different parameters of flow and glucose metabolism measured at PET are described in Table I.

Morphologic analysis. One transmural biopsy specimen (20 mm 14-gauge needle) was obtained from the dysfunctional region before induction of extracorporeal circulation. The samples were immediately fixed in 3\% glutaraldehyde buffered at $\mathrm{pH} 7.4$, then postfixed in osmium tetroxide and embedded in Epon fixative. ${ }^{10}$ Semithick sections stained with toluidine blue and periodic
acid-Schiff reaction were prepared for each sample. Light microscopy was used to quantify cellular alterations (mainly the loss of myofibrils and the percentage of intracellular volume occupied by glycogen) and the amount of extracellular matrix. ${ }^{12,17}$ Each section was examined by means of quantitative morphometry as previously described. ${ }^{12,17}$ This procedure was repeated several times on different zones of the biopsy specimen.

Statistical analysis. Values are expressed as mean \pm one standard deviation. Differences in discrete variables between patients with and without recovery were compared by means of $\chi^{2}$ tests, whereas those in continuous variables were compared by use of the Student's $t$ test for unpaired data. The correlation between PET and morphometric parameters was investigated by use of linear regression analysis. All $p$ values less than 0.05 were considered indicative of a statistically significant difference.

\section{Results}

According to the changes in left ventricular ejection fraction and regional wall motion score at follow-up, 34 patients were considered to have functional improvement, whereas 19 patients were considered to have persistent dysfunction. The clinical characteristics of these two groups of patients are shown in Table II. The two groups were comparable with respect to age, sex, extent and severity of coronary artery disease, and extent of left ventricular dysfunction. Previous myocardial infarction was more prevalent in patients with persistently dysfunctional myocardium. Such patients also had larger end-systolic and end-diastolic volumes (see Table II). Fig. 1 shows the changes in ejection fraction and left ventricular volumes resulting from coronary 


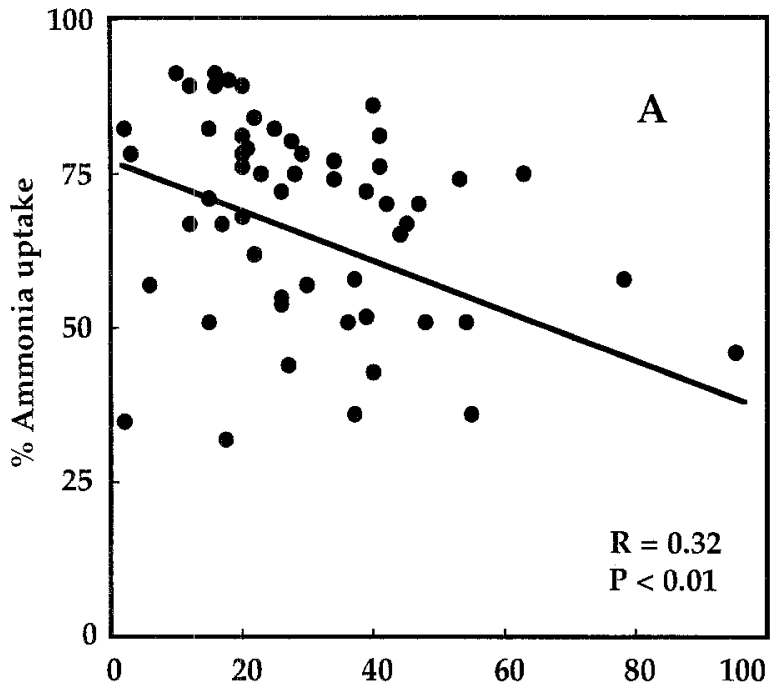

Fibrosis (\% of biopsy surface)

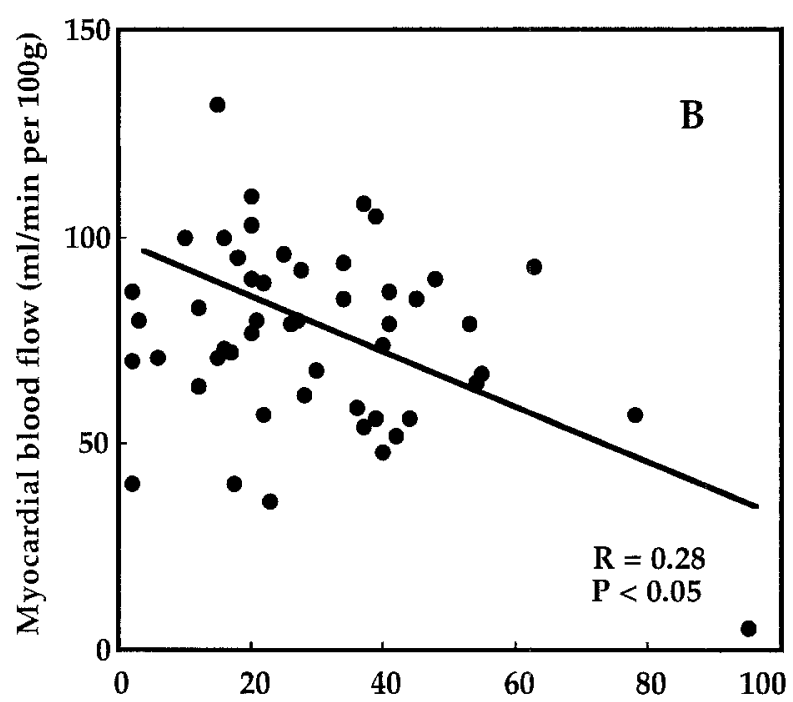

Fibrosis (\% of biopsy surface)

Fig. 3. Scatterplot showing the relationship between tissue fibrosis and relative ammonia uptake (A) and absolute myocardial blood flow $(\mathbf{B})$.

Table III. PET and morphologic characteristics

\begin{tabular}{|c|c|c|c|c|}
\hline & $\begin{array}{c}A l l \\
(n=53)\end{array}$ & $\begin{array}{c}\text { Reversible } \\
\text { dysfunction } \\
(n=34)\end{array}$ & $\begin{array}{l}\text { Persistent } \\
\text { dysfunction } \\
(n=19)\end{array}$ & $p$ Value \\
\hline $\begin{array}{l}\text { Myocardial blood flow } \\
\left(\mathrm{ml} \cdot[\mathrm{min} \cdot 100 \mathrm{gm}]^{-1}\right)\end{array}$ & $81 \pm 21$ & $90 \pm 29$ & $63 \pm 20$ & 0.002 \\
\hline Percent ammonia uptake & $67 \pm 17$ & $71 \pm 15$ & $58 \pm 17$ & 0.01 \\
\hline $\begin{array}{l}\text { Myocardial glucose uptake } \\
\left(\mu \mathrm{mol} \text { " }\left[\mathrm{min} \cdot 100 \mathrm{gm}^{-1}\right)\right.\end{array}$ & $37 \pm 17$ & $42 \pm 16$ & $30 \pm 14$ & 0.01 \\
\hline Percent FDG uptake & $72 \pm 20$ & $77 \pm 19$ & $62 \pm 17$ & 0.01 \\
\hline FDG/ammonia & $1.25 \pm 0.31$ & $1.21 \pm 0.30$ & $1.32 \pm 0.33$ & NS \\
\hline Percent tissue fibrosis & $27 \pm 16$ & $24 \pm 15$ & $37 \pm 19$ & 0.003 \\
\hline Percent altered cardiomyocytes & $35 \pm 16$ & $38 \pm 15$ & $29 \pm 18$ & NS \\
\hline
\end{tabular}

NS, Not significant.

revascularization in the two groups of patients. Left ventricular ejection fraction increased by $12 \% \pm 7 \%$ in patients with reversible dysfunction and decreased by $6 \% \pm 9 \%$ in patients with persistent dysfunction. Similarly, end-systolic volume decreased by $29 \pm 21 \mathrm{ml}$ in patients with reversible dysfunction and increased by $27 \pm 31 \mathrm{ml}$ in those with persistent dysfunction.

The PET and morphologic characteristics of the two groups of patients are summarized in Table III. Reversibly dysfunctional segments showed higher levels of absolute and relative myocardial blood flow and glucose uptake than segments with persistent dysfunction. They also had a lesser increase in extracellular matrix and tended to show more altered cardiomyocytes and glycogen accumulation. Similar results were obtained in the subgroups of patients with an initial ejection fraction less than $30 \%$.

As shown in Fig. 3, significant correlations were observed between the amount of extracellular matrix and both absolute $(A)$ and relative $(B)$ levels of regional myocardial blood flow. Similarly, absolute regional myocardial glucose uptake correlated with the density of altered cardiomyocytes (Fig. 4, $A$ ) and with the amount of glycogen accumulated in these cells (Fig. 4, B). There was no significant correlation between relative FDG uptake and the morphologic characteristics. 


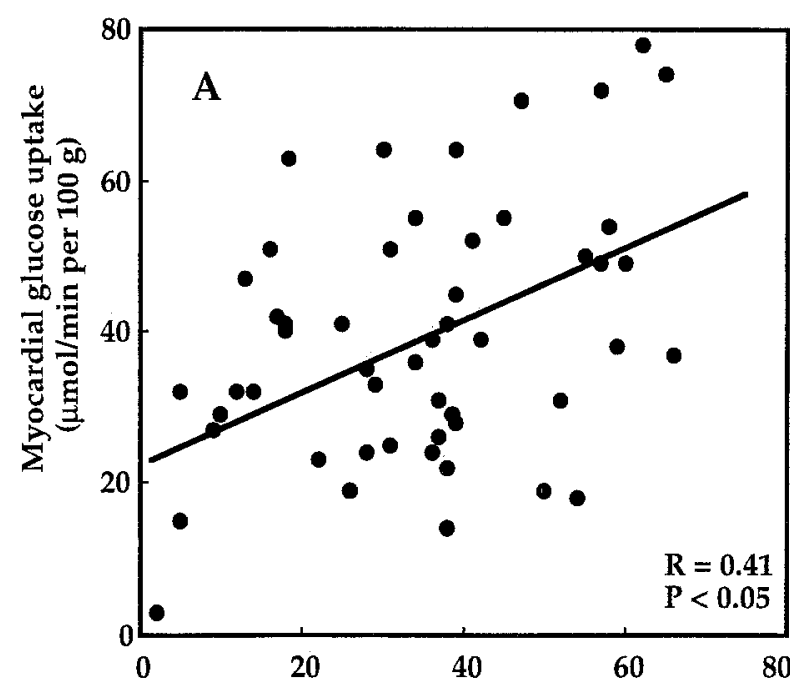

Altered cardiomyocytes ( $\%$ of surface)

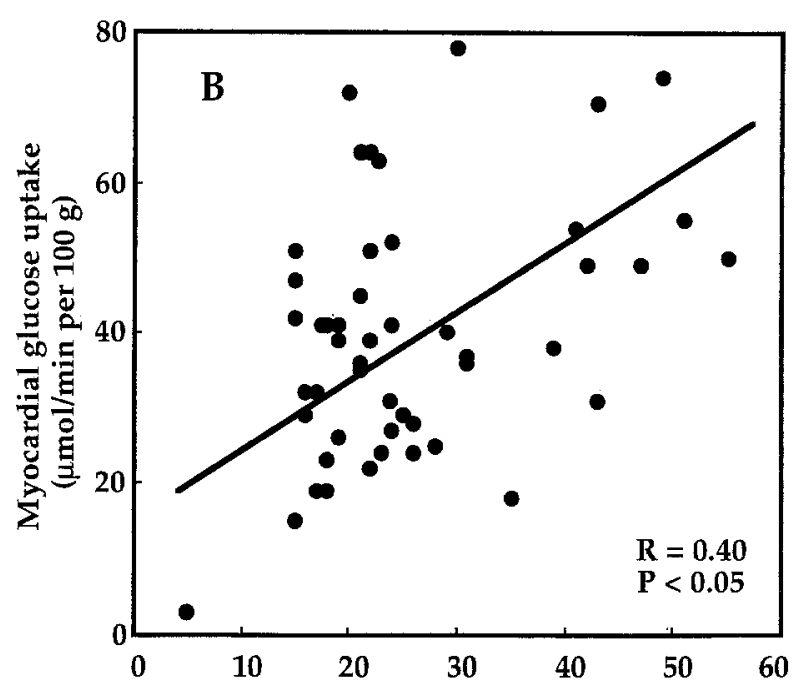

Glycogen content ( $\%$ of cell volume)

Fig. 4. Scatterplot showing the relationship between absolute myocardial glucose uptake and the surface of the biopsy covered by altered cardiomyocytes (A) and the percentage of accumulation of glycogen in altered cardiomyocytes (B).

\section{Discussion}

Each year in the United States, more than 200,000 patients undergo CABG. Although this intervention can improve symptoms and lessen disability in almost every patient, it probably confers the greatest advantages and prolongs survival in the subgroup of patients with severe depression of left ventricular function. ${ }^{2}$ Innovations in operative techniques, myocardial protection, and postoperative care have undoubtedly contributed in important ways to these outstanding results. Yet not every patient with coronary artery disease does benefit from surgical revascularization, for $\mathrm{CABG}$ continues to entail significant immediate risks, particularly when global left ventricular function is severely depressed. Careful selection of individual patients with left ventricular dysfunction for surgical revascularization is therefore mandatory. The present study shows that the recovery of regional contractile function after CABG correlates significantly with preoperative myocardial perfusion and glucose uptake by PET; it correlates as well with the extent and severity of morphologic changes in the underlying tissue, mainly fibrosis and the amount of structurally altered cardiomyocytes. These data thus further substantiate the value of metabolic imaging with PET in the preoperative selection of patients with left ventricular dysfunction for CABG.

Previous clinical studies have shown that chronic regional dysfunction caused by coronary artery disease does not always result from irreversible tissue damage and, to some extent, can be reversed by restoration of blood flow. ${ }^{1-3,18-20}$ The current study confirms and extends these earlier reports. In this study, regional and global left ventricular function improved significantly in 34 of the initial 53 patients after revascularization and remained depressed in only 19 patients. In addition, our data indicate that the degree of improvement in left ventricular function after adequate revascularization is dependent on the severity of preexisting irreversible tissue damage. Segments with persistent postoperative dysfunction indeed showed almost twice as much tissue fibrosis and contained fewer metabolically active and thus viable cardiomyocytes than segments with reversible dysfunction. Obviously, revascularization of such fibrotic, myocyte-depleted segments is unlikely to reverse the underlying structural abnormalities and to restore contraction. Interestingly enough, the structural characteristics of both reversibly and irreversibly damaged myocardium were found to correlate significantly with the PET flow and metabolic findings. Specifically, the extent of tissue fibrosis correlated with both absolute and relative levels of myocardial blood flow, whereas the density of altered cardiomyocytes correlated with the amount of myocardial glucose or FDG uptake. This suggests that these two parameters (tissue 
fibrosis and the density of altered cardiomyocytes) are the structural basis underlying the ability to predict functional recovery by the measurement of residual tissue perfusion and glucose uptake by PET.

The current study confirms the presence of structurally altered cardiomyocytes in ischemically jeopardized myocardium. The morphologic features of these cells have been described elsewhere. ${ }^{11,12,17}$ At present, the mechanisms leading to their occurrence remain poorly understood and are at best sketchy. However, there is increasing evidence that these mechanisms could be the consequence of a dedifferentiation process, inasmuch as their phenotype closely resembles that of fetal cardiomyocytes. ${ }^{21}$

This study has several limitations, which have already been acknowledged. The relation between the structural alterations seen with the microscope and the findings with PET requires much caution, particularly in view of the small size of the biopsy samples, which was imposed by safety considerations. One must nonetheless assume that the morphologic alterations were evenly distributed in the area of interest-not necessarily true in patients with a previous infarction. Also, the fact that preoperative studies were performed days to weeks before the operation and that postoperative studies occurred months after the operation raises the possibility that intervening events could have influenced the outcome in individual patients. This is unlikely, however, because none of the patients had any adverse events before the operation or between the operation and the postoperative follow-up studies. Finally, the current study does not allow us to determine whether structural reversibility contributes to the functional improvement after revascularization. For obvious ethical reasons, it has not yet been possible to obtain a second surgical biopsy specimen at a distance from the revascularization procedure and to test this hypothesis.

\section{Conclusions}

We have described the structural, flow, and metabolic correlates of the recovery of contractile function after revascularization in patients with chronic ischemic anterior wall dysfunction. The data show that the recovery of regional contraction is related to the extent and severity of tissue fibrosis, to the density of metabolically active cardiomyocytes, and to resting myocardial blood flow and glucose uptake.
The PET studies were performed with the help of $\mathrm{C}$. Michel, T. Baudhuin, and C. Grandin. Radiopharmaceuticals were prepared by D. Labar and M. Cogneau. The morphologic studies were prepared by F. Thoné. Their expertise is greatly appreciated. We are indebted to A. Robert, $\mathrm{PhD}$, consultant statistician, for reviewing the statistical analysis.

\section{REFERENCES}

1. Braunwald E, Rutherford JD. Reversible ischaemic left ventricular dysfunction: evidence for "hibernating myocardium." J Am Coll Cardiol 1986;8:1467-70.

2. Rahimtoola SH. A perspective on the three large multicenter randomized clinical trials of coronary bypass surgery for stable angina. Circulation 1985;72(Suppl):V123-35.

3. Rahimtoola SH. The hibernating myocardium. Am Heart J 1989;117:211-21.

4. White HD, Norris RM, Brown MA, Brandt PWT, Whitlock RML, Wild CJ. Left ventricular end-systolic volume as the major determinant of survival after recovery from myocardial infarction. Circulation 1987;76:44-51.

5. European Coronary Surgery Study Group. Long term results of prospective randomized study of coronary artery bypass surgery in stable angina pectoris. Lancet 1982;2:1173-80.

6. Taegtmeyer H. Energy metabolism of the heart: from basic concepts to clinical applications. Curr Probl Cardiol 1994;19: 57-116.

7. Marwick TH, MacIntyre WJ, Lafont A, Nemec JJ, Salcedo EE. Metabolic responses of hibernating and infarcted myocardium to revascularisation: a follow-up study of regional perfusion, function and metabolism. Circulation 1992;85: 1347-53.

8. Tamaki N, Yonekura Y, Yamashita K, Saji H, et al. Positron emission tomography using fluorine-18 deoxyglucose in evaluation of coronary artery bypass grafting. Am J Cardiol 1989;64:860-5.

9. Tillisch J, Brunken R, Marshall R, et al. Reversibility of cardiac wall motion abnormalities predicted by positron tomography. N Engl J Med 1986;314:884-8.

10. Flameng W, Wouters $L$, Sergeant $P$, et al. Multivariate analysis of angiographic, histologic, electrocardiographic data in patients with coronary heart disease. Circulation 1984;70:7-17

11. Vanoverschelde JLJ, Wijns W, Depré C, et al, Mechanisms of chronic regional postischemic dysfunction in humans: new insights from the study of non-infarcted collateral dependent myocardium. Circulation 1993;87:1513-23.

12. Depré C, Vanoverschelde JL, Melin JA, et al. Structural and metabolic correlates of the reversibility of chronic left anterior ischemic dysfunction in humans. Am J Physiol 1995;268: H1265-75.

13. American Society of Echocardiography Committee on standards. Recommendations for quantitation of the left ventricle by two-dimensional echocardiography. J Am Soc Echocardiogr 1989;2:358-67.

14. Knuuti MJ, Nuutila P, Ruotsalainenn U, et al. Euglycemic hyperinsulinemic clamp and oral glucose load in stimulating myocardial glucose utilisation during positron emission tomography. J Nucl Med 1992;33:1255-62.

15. Bol A, Melin JA, Vanoverschelde JLJ, et al. Direct comparison of N-13 ammonia and O-15 water estimates of perfusion 
with quantitation of regional myocardial perfusion by microspheres. Circulation 1993;87:512-25.

16. Gambhir SS, Schwaiger M, Huang SC, Krivokapitch J, Schelbert HR, Nienaber CA, et al. A simple noninvasive quantification method for measuring myocardial glucose utilization in humans employing positron emission tomography and ${ }^{18}$ F-deoxyglucose. J Nucl Med 1989;30:359-66.

17. Borgers M, Thoné F, Wouters L, Ausma J, Shivalkar B, Flameng W. Structural correlates of regional myocardial dysfunction in patients with critical coronary artery stenosis: Chronic hibernation? Cardiovasc Pathol 1993;2:237-45.

18. Gropler RJ, Siegel BA, Sampathkumaran K, et al. Dependence of recovery of contractile function on maintenance of oxidative metabolism after myocardial infarction. J Am Coli Cardiol 1992;19:989-97.

19. Gropler RL, Geltman EM, Sampathkumaran K, et al. Functional recovery after coronary revascularization for chronic coronary artery disease is dependent on maintenance of oxidative metabolism. J Am Coll Cardiol 1992;20:569-77.

20. de Silva R, Yamamoto Y, Rhodes CG, et al. Preoperative prediction of the outcome of coronary revascularization using positron emission tomography. Circulation 1992;86:1738-42.

21. Ausma J, Schaart G, Thoné F, et al. Chronic ischemic viable myocardium: aspects of dedifferentiation. Cardiovasc Pathol 1995;4:29-37.

\section{Discussion}

Dr. L. Henry Edmunds, Jr. (Philadelphia, Pa.). Because these are patients, you probably knew the ejection fractions before and after the operation. How many of the 40 patients had an improvement of $5 \%$ or more in their ejection fraction after the operation and how well did that correlate with your assay and with the PET scan?

Dr. Dion. By definition-according to the design of this study-all of the patients in the "viable" group (34/53) had an improvement by at least $5 \%$ in their ejection fraction after the operation. The correlation between PET scan prediction of recovery and functional recovery was as follows: considering FDG alone and a "cutoff" of 60\%, the sensitivity was $88 \%$ and the specificity $50 \%$; considering flow alone and a "cutoff" of $64 \mathrm{ml} / \mathrm{min}$ per $100 \mathrm{gm}$, the sensitivity was $91 \%$ and the specificity $56 \%$; finally, considering the mismatch and a "cutoff" of flow/FDG less than 1.2 , the sensitivity was only $66 \%$ and the specificity $44 \%$. Therefore, to improve the prediction of functional recovery provided by the PET scan, namely its specificity, we need another noninvasive tool in the preoperative period, ideally, stress echocardiography.

Dr. Edward D. Verrier (Seattle, Wash.). Dr. Buckberg, last year your group published a significant article in Circulation concerning the mismatch between flow and metabolism. You were able to devise a scale that quantitated the expected percent of recovery that may be achieved by using a PET scan with the myocardial viability index of the deoxyglucose. How does that fit into this assessment, in which there is not so much of a correlation between the flow and metabolism?

Dr. Gerald D. Buckberg (Los Angeles, Calif.). The study at UCLA showed an approximately $80 \%$ improvement in function with a mismatch between flow and deoxyglucose. The greatest improvement occurred when there was a large mismatch $(\geq 18 \%)$ with $107 \%$ improvement, compared with minimum recovery (approximately $34 \%$ ) with minimal or no PET mismatch ( $\leq 5 \%$ ). Consequently, the largest mismatch showed the greatest clinical benefit.

Dr. Verrier. Dr. Dion, how many patients of your group were actually referred for transplantation but were instead treated by revascularization on the basis of the results of this technology?

Dr. Dion. None of these patients was ever considered for heart transplantation. Every patient with an ejection fraction less than $35 \%$ undergoes an extensive battery of viability tests, namely, dobutamine stress echocardiography, thallium scintigraphy with reperfusion, and PET scan. If viability is detected and some functional recovery anticipated, we always attempt myocardial revascularization first.

Dr. James K. Kirklin (Birmingham, Ala.). In using this as a prognostic test in deciding who would benefit from revascularization, how did you separate out the possibility of loss of cell viability during the operation? How did you separate out the possibility of losing cells in the operating room, that is, of imperfect myocardial protection? Is that a possibility that that would influence the results of your viability testing?

Dr. Dion. Predicting the relative quality of the perioperative myocardial protection, even when based on the preoperative coronary angiogram, looks hazardous to me. Theoretically, the combination of antegrade and retrograde cardioplegia should optimally protect the myocardium even in the presence of a diffuse triple-vessel disease. In our series, the cardiac enzymes were measured every 4 hours after the operation, and the enzyme curves were flat. There was no pathologic change in the electrocardiogram. Also, the internal thoracic artery graft to the left anterior descending coronary artery was patent at angiographic restudy in all patients. Finally, no cardiac adverse events occurred between the operation and the time of assessment of cardiac function. Therefore I believe that the prognostic value of our viability testing was not influenced by intercurrent perioperative alterations.

Dr. Verrier. The question that remains is when to use this sort of expensive technology to determine viability. The combination of these tests can cost in excess of a number of a thousand dollars. Certainly at the University of Washington we use them, but rarely, and almost always in patients with ejection fractions of $20 \%$, in whom we are trying to distinguish between transplantation and revascularization. 